\title{
Accountability Measures in Higher Education and Academic Workload: A Ten-Year Comparison
}

\section{Brock Brock Education}

A journal of educational research and practice 2021 Vol. 30 (2) 116-136

https://journals.library.brocku.ca/brocked

\section{Silvia Mirlene Nakano Koga*, Alexandre Beaupré-Lavallée, Olivier Bégin-Caouette} Université de Montréal

\begin{abstract}
At the core of New Public Management (NPM) reforms sits the concept of accountability of publicly funded organizations. In Canada, it is suggested that provinces have increased the number of accountability procedures imposed on universities and that those measures would have had an impact on professors' academic workload. This study discusses the evolution of academic workload and evaluation of professors' activities over the last decade, as well as the current distribution of academic workload among the university staff. It relies on the Canadian faculty's perspectives collected through the 2007 Changing Academic Profession (CAP) study ( $n=1151$ ) and the 2017 Academic Profession in the Knowledge Society (APIKS) study ( $n=2968$ ). Findings suggest that academic workload increased significantly in the 10 years that academic activities are significantly more evaluated, although by academics themselves in a smaller proportion, and that the administrative burden lies more heavily on female and senior faculty members. Descriptive statistics and a MANOVA comparing the scores of five variables in 2007 and 2017 suggest that academic workload increased significantly in 10 years, academic activities are significantly more evaluated, although less by academics themselves, female academics report dedicating more time to administrative tasks and being more frequently evaluated, and senior administrative staff and external reviewers are perceived as being more involved in the evaluation of academic activities in 2017 than in 2007. Our interpretation is that accountability measures could increase professors' administrative burden and grant more authority to non-academic staff.

Keywords: accountability, academic workload, academic profession, new public management, Canadian universities

*silvia.mirlene.nakano.koga@umontreal.ca
\end{abstract}


The knowledge society has revalued the university and its production as key factors of economic progress. In this new context, university professors have become central both to produce valuable knowledge and to train a highly qualified workforce (Finkelstein \& Jones, 2019). Following World War II, member countries of the Organisation for Economic Cooperation and Development (OECD) allocated generous funding to universities and technicaleducation institutions to increase access, thus contributing to higher education systems' massification and, in some cases, universalization. However, during the late 1970s and the 1980s, economic crises put pressure on public purses and governments have looked for reforms to preserve welfare while limiting states' contribution.

Around the same period, a managerial paradigm, the New Public Management (NPM), took hold in the public administration and universities with the implementation of accountability measures aimed at increasing institutional efficiency and faculty performance, and justifying their use of public funds. These measures have impacted institutional differentiation and governance, tuition fees and students' role within institutions, and have been perceived to challenge academics, such as traditions of institutional autonomy, collegiality (Marini \& Reale, 2016) and academic freedom (Marginson, 2009), as well as the traditional ethos of the academic profession (Enders et al., 2009). Studies also suggest that NPM has focused on the transformations of academic life, highlighting the individual strategies to adapt to accountability measures (Gonzales, 2012; Hall \& Ferris, 2011).

Relying on the perspectives of Canadian professors, the objective of this paper is to examine how faculty workload and academic activities' evaluation have evolved between 2007 and 2017, in a context marked by additional demands put on higher education systems, the professionalization of academic administration, and an increase in paperwork (Allen, 2011 ; Gopaul et al., 2016; Jones, 2011 ). This article also explores the impact of accountability on different groups of academics as well as the shift of power from faculty members to senior administrators (Kyvik, 2013; Link et al., 2007; Tight, 2010).

\section{Conceptual Framework}

The conceptual framework for this article draws on the sociology of work, is anchored around the concept of accountability, and relies on an extensive literature review to operationalize the manifestations of this concept in the context of the higher education workplace.

\section{New Public Management and Higher Education}

The transition from an elitist higher education system to a high participation system (Trow, 1973) during the 1960s and 1970s in industrialized countries was followed by economic cracks, market restrictions, and other factors that brought discontent of the public and loss of confidence on public institutions. This crisis could have facilitated changes in the political and 
economic scales with neoliberal ideology flavours (Crespo et al., 2011 ; Newton, 2001). The NPM paradigm was one of the manifestations of the imperative ideology to face the crisis. NPM originally focused on the transformation of institutions of the public sector and promised their automatic de-bureaucratization with the introduction of managerial practices inspired by the private sector. This model mainly focused on holding the public administration accountable for the results they were expected to produce within a restrictive financial framework (Craig et al., 2014).

In most OECD countries, (public) universities have been beneficiaries of state support and consequently regarded as para-public organizations expected to be accountable to the State and their users (Eastman et al., 2018). Broucker and De Wit (2015) have identified four NPMinspired and often interrelated reforms that have altered academic work: marketization, budgetary reforms, a managerial style of governance, and accountability and performance evaluation. Regarding this fourth category, NPM has increased human resources' performance monitoring, and the quality assessment of teaching, research, and external activities. Although peer evaluation and mentoring have been current practices within academia (Buchanan et al., 2008), the new evaluation regime requests non-academic, external actors and organizations to carry out this task (O'Meara et al., 2017). As Neave (1998) put it, the evaluating State includes various quality experts, key indicators, auditors, and accreditation bodies. Performance evaluation was, however, not solely the result of state pressure, but also of a marketization process in which universities monitor their activities as part of strategies to compete with other universities for students (Buchanan et al., 2008), research grants, and profit-generating activities (Gopaul et al., 2016). Finkelstein and Jones (2019) summarize what this combination of massification, economic crisis, and marketization brought to universities:

The imperative to accommodate demands for increased access globally has placed enormous pressures on the national higher education systems to economize, to do more with less. This has translated effectively into placing greater workloads on individual faculty, allowing the working environment and conditions to deteriorate, and, in many countries, precipitating a wholesale reconfiguration of the profession to include a growing army of contingent workers to handle the workload increase at lower cost. (pp. 1-2)

As the following section suggests, this cultural and institutional vocabulary of accountability increasingly used to depict core academic missions (Craig et al., 2014) would not be without an impact on faculty members' academic workload and professional ethos.

\section{Accountability and Academic Work}

The literature review reveals several consequences of accountability measures on administrative and paperwork burden, evaluation occurrences, and professional exhaustion. 
Firstly, studies suggest that the increasing complexification of universities' activities (with regard to research ethics, fundraising, accommodation for students with disabilities, workplace placement, or international partnerships), in an environment marked by competition and efficiency, has increased the pressures put on academics (GuzmánValenzuela, 2018), either directly or indirectly. In the United Kingdom, Newton (2001) reported figures suggesting that quality assessment had increased paperwork and staff time tenfold in the last 10 years. In the same country, Tight (2010) noted that the administrative burden had increased and represented a quarter of professors' working hours. In Canada, Crespo and Bertrand (2013) used institutional data from one research-intensive university to show an increase in faculty workload between 1996 and 2006. This increase was partly explained by a rise in students per class as well as other activities related to "institutional functioning," such as preparation of research projects, paperwork, and reports. Regarding indirect influence, universities' complexification has increased the demand for hiring professionals. For Kouritzin (2020), those professionals have also contributed to an increase in faculty workload: "the burden for the faculty who must jump through additional administrative hoops" (p. 1106). Studies (e.g. O’Meara et al., 2017) however suggest that this added paperwork burden does not necessarily imply an increase in the number of working hours, as other tasks might be put aside.

Secondly, new forms of surveillance, monitoring, and reporting has been implemented to make institutions and individuals accountable (Craig et al., 2014). Organizations external to universities have gained a monitoring power over them (O'Meara et al., 2017), and this steering at a distance has led to the multiplication of evaluation occurrences within universities. Geurts and Maassen's (2005) study of evaluation practices in four European higher education systems suggested that academics reported being evaluated more often and by different types of actors. Evaluations were perceived as more managerial than collegial and often led by department chairs and senior administrative staff. A Canadian study in three Quebec research-intensive universities also noted that, in addition to an increase in the number of evaluations, those evaluations were no longer circumscribed to peer academics and often accomplished by or for non-academic administrative staff (Kouritzin, 2020). The student evaluation of teaching (SET) constitutes a particular example in that regard. User satisfaction towards services received is an integral part of NPM (Crespo et al., 2011) and, in universities, it takes the form of SET that are increasingly used as part of faculty promotion (Zhao \& Gallant, 2012), although its validity has been contested by some scholars (Boring, 201 7; Cook et al., 2020; Hornstein, 2017; Mitchell \& Martin, 2021).

Thirdly, beyond the burden of the "audit culture" (Shore, 2008), accountability measures could have contributed to an increase in faculty members' reported stress, anxiety, and exhaustion. Craig et al. (2014) indicated that "the strong pressure academics are under to comply with accountability metrics seems likely to explain why many seem too busy to talk to their 
colleagues" (p. 12), pointing to a possible influence on academics' self-isolation. According to Kouritzin (2020), symptoms of stress and disengagement may be associated with a "workload creep" (p. 1094), defined as the increased pressures of market metrics imposed on professorial tasks. Other studies also suggested that a surveillance environment would result in risk aversiveness, and a loss in academics' professional confidence (Anderson, 2006; Newton, 2001; Trow 1994).

In accordance with our objective to examine how faculty workload and academic activities' evaluation evolved over the last decade, the literature cited above would suggest that, in a context marked by NPM, accountability measures could affect faculty workload through administrative and paperwork burden, evaluation occurrences, and professional exhaustion.

\section{Workload and Different Groups of Professors}

While accountability induces an additional pressure on academics, its impacts do not affect all faculty members equally. The paperwork and administrative burden might, on the contrary, lie differently depending on institutional or individual (sociodemographic) factors. Data from the Changing Academic Profession (CAP) study revealed that faculty members report an unequal distribution of tasks according to gender or salary levels, and concomitantly, various levels of strain and dissatisfaction (Jones, 2011 ; Porter \& Umbach, 2001).

Gender seems to be a core factor modulating the impact of accountability-induced workload. Link et al. (2007) observed that women professors in American universities spent more time on (internal or external) service activities than on research. O'Meara et al. (2017) remarked that female faculty was perceived as being naturally more inclined towards "organizational housekeeping" and that, for them, refusing to perform administrative tasks came at a greater risk; the risk seems even higher for women from minorities. Craig et al. (2014) reached similar conclusions regarding accountability and auditing practices generating a greater disadvantage for female professors' career advancement. The burden would also affect differently faculty members from different ranks: full professors were more likely to devote themselves to local and international services (consultants) than to research and teaching. While assistant professors were expected to do more research in order to be promoted, associate professors would be the most involved with administrative tasks and the least satisfied with their distribution (Link et al., 2007; O’Meara et al., 2017).

Our objective is to contrast those assumptions and findings of the literature with the changes in academic workload, as reported by Canadian professors. More precisely, using the data from the 2007 CAP study and the 2017 APIKS study, this paper aims to answer the three following research questions:

1. Are there significant differences in Canadian university professors' self-reported 
workload between 2007 and 2017 ?

2. By whom were professors' academic activities evaluated in 2007 and 2017 ?

3. In 2017, were some faculty members more involved than others in dealing with administrative tasks?

\section{Methodology}

To respond to our research questions, we performed statistical analyses on two databases.

\section{Data Collection}

This study is based on the Canadian chapter of the 2007 CAP study, conducted in 18 countries, and the 2017 APIKS study, conducted in 25 countries. For the CAP study, 6,693 invitations to participate in a survey were sent to all professors at 47 Canadian universities, with a response rate of $17.21 \%$. For the APIKS study, invitations were sent to professors at 64 Canadian universities, and 2,968 completed the questionnaire, which corresponds to a response rate of $11.97 \%$. The two instruments were almost identical and included more than 50 items regarding professors' perceptions of academic work, working conditions, work satisfaction, research activities, teaching activities, working history, as well as their sociodemographic characteristics. Considering that it was not possible to link individuals' responses from 2007 to 2017, that the sampling processes were different and that surveys were 10 years apart, we considered the 2007 and 2017 as independent samples.

To examine samples' representativeness, we compared both samples with data from Statistics Canada (2019) and the Canadian Association of University Teachers (CAUT, 2019) Almanac of Post-Secondary Education. As shown in Table 1, the proportion of female participants was higher than the proportion of females in the overall faculty population. Associate professors were slightly over-represented in 2007, while assistant professors were slightly underrepresented in 2017, and full professors were slightly over-represented both years. Participants' average age was 47 in 2007 (mean year of birth being 1959) and 52 in 2017 (mean year of birth being 1965). Despite those deviations, samples were considered as representative of the larger population of Canadian faculty by other studies (Gopaul et al., 2016; Karram Stephenson, Jones, Bégin-Caouette, \& Metcalfe, 2020). 
Table 1

Participants' Gender and Academic Rank Compared to the General Population of Canadian University Professors

\begin{tabular}{lcccc}
\hline & $\begin{array}{c}2006-2007 \\
\text { population* }\end{array}$ & $\begin{array}{c}2007 \\
\text { sample }\end{array}$ & $\begin{array}{c}2017-2018 \\
\text { population** }\end{array}$ & $\begin{array}{c}2017 \\
\text { sample }\end{array}$ \\
\hline $\begin{array}{l}\text { Gender } \\
\text { Female }\end{array}$ & $33 \%$ & $41 \%$ & $41 \%$ & $51 \%$ \\
$\quad$ Male & $67 \%$ & $59 \%$ & $59 \%$ & $49 \%$ \\
Academic rank & & & & \\
Assistant & $27 \%$ & $29 \%$ & $18 \%$ & $16 \%$ \\
Associate & $33 \%$ & $35 \%$ & $37 \%$ & $37 \%$ \\
Full & $35 \%$ & $36 \%$ & $36 \%$ & $41 \%$ \\
\hline
\end{tabular}

Note. *Adapted from Statistics Canada (2019) Table 37-10-0076-01. **Adapted from CAUT Almanac (CAUT, 2019).

\section{Data Analyses}

This study used IBM SPSS 25. To examine if there was a significant difference in professors' perception between 2007 and 2017, we merged the CAP and APIKS databases $(n=4081)$. Three survey items were used to create five dependent variables (DVs): (a) for all of your professional activities, how many hours do you spend in a normal week, when classes are in and not in session, on the following [teaching, research and service] activities?; (b) who regularly assesses your teaching, research, and service activities?; (c) to what extent do you agree with the following statement: there is a cumbersome administrative process [5-point Likert scale]? The five variables we created reflect the evaluative and administrative components of faculty workload:

- DV1 Working hours per week.

- DV2 Proportion (\%) of time dedicated to administration.

- DV3 Number of evaluation occurrences.

- DV4 Proportion (\%) of participation to evaluation by professors.

- DV5 Perception of administrative cumbersomeness.

To obtain a typical annualized average week of hours worked in DV1, we created a weighted variable giving $60 \%$ to weeks with classes and $40 \%$ to weeks without classes.

Our analyses also included four independent variables (IVs): year of survey (2007 or 2017), faculty rank (assistant, associate, and full professors), gender, and age at the time of completing the survey. For gender, after noting that, in 2007, the category "other" did not exist, 
we removed the 26 participants who, in 2017 , checked that category. We also created five categories of age groups.

To answer our first research question, we calculated descriptive statistics and carried out a parametric MANOVA (Wilks' Lambda) to examine differences in faculty responses between 2007 and 2017 (IV = Year of survey) for the five DVs. We measured the normality of the distribution of DVs and found that the estimated skewness (s) and kurtosis (k) were between -1 and 1 , except for the DV2 variable ( $\mathrm{s}=2.014, \mathrm{k}=5.155)$. In the latter we proceeded to a MannWhitney U post-hoc test, while for the rest we ran post-hoc Student's t-tests. To answer our second question, we disaggregated DV4 by categories of evaluators and academic activities. To answer our third question, we disaggregated the five DVs by gender, age, and faculty rank.

\section{Limitations}

Some methodological and conceptual limits might have restrained or biased our analysis. First, one variable's (DV2) kurtosis and asymmetry were outside the tolerance margins. Although we performed non-parametric tests on this variable, our MANOVA model assumed that the assumptions of normality and homoscedasticity were achieved, which may have undermined its reliability. Moreover, we proceeded to a between-subject analysis of variance, participants' anonymity prevented us from determining if the 2007 and 2017 samples were, in fact, independent or if some responses came from the same individuals. Finally, in addition to this survey being based uniquely on professors' perceptions of their work, it must be highlighted that our study cannot confirm any causal link between what the literature characterizes as an increase in accountability measures and variations in academics' self-reported workload. Our interpretations are thus circumstantial and must be treated with caution. Nonetheless, this study represents a first step in examining the evolution of academics' perception of university work in the last 10 years and the first of this magnitude analyzing what groups of academics bear the burden of administrative tasks.

\section{Findings}

This section is divided into the three research questions that this paper sought to answer.

\section{Are There Significant Differences in Canadian University Professors' Self-Reported Workload Between 2007 and $2017 ?$}

As shown in Table 2, mean scores for four of the five DVs increased between 2007 and 2017. Compared to participants in 2007, participants in 2017 report working more hours per week, dedicating more time to administrative tasks, being evaluated more often, and facing a more cumbersome administrative process. Professors, however, report that their teaching, research, and service activities are less frequently evaluated by peer academics in 2017 than they were in 2007. 
Table 2

Mean Scores of Dependent Variables in 2007 and 2017

\begin{tabular}{llcccc}
\hline \multicolumn{1}{c}{ Variables } & Year & $n$ & $M$ & $S D$ \\
\hline \multirow{2}{*}{ DV1 Working hours per week } & 2007 & 1149 & 43.40 & 14.85 \\
& \multirow{2}{*}{ DV2 \% time dedicated to administrative tasks } & 2017 & 2743 & 45.27 & 14.10 \\
& \multirow{2}{*}{ Number of evaluation occurrences } & 2007 & 1108 & $16 \%$ & 0.15 \\
DV3 & 2017 & 2743 & $18 \%$ & 0.15 \\
& \multirow{2}{*}{ DV4 $\%$ of participation to evaluation by professors } & 2007 & 1284 & 6.25 & 4.43 \\
& & 2017 & 2797 & 6.87 & 3.78 \\
DV5 & 2007 & 1066 & $36 \%$ & 0.23 \\
& & 2017 & 2747 & $32 \%$ & 0.24 \\
\end{tabular}

In order to examine if variations were statistically significant, we proceeded to a betweensubject one-way MANOVA (Wilks' Lambda) on the five DVs and for which the year of the survey was the IV. Findings suggest that the means of the scores attributed by participants to the five variables taken together in 2017 is significantly different than the mean of the scores attributed by participants in 2007, Wilks' Lambda $=0.986, F(5,3674)=10.804, p=0.000$, partial etasquared $\eta^{2}=0.014$ (small size of the amplitude effect of the difference between the means).

As presented in Table 3, post-hoc t-tests were carried out for the four variables which data follow normal distribution. Findings suggest that differences between 2007 and 2017 are statistically significant $(p<0,05)$, although Cohen tests indicated that the size effect of those significant differences is small ( $d$ cohen $\leq 0.2$ ). Participating faculty members therefore report working significantly more hours per week, being evaluated more often, being less evaluated by peer faculty members, and having to face a more cumbersome administrative process.

DV2 did not follow a normal distribution, so we performed a Mann and Whitney non-parametric test and obtained that the mean rank of 2017 was significantly higher than that of 2007 ( $p<$ $0,01)$, but the difference is of small magnitude $\left(\eta^{2}=0.01\right)$. In other words, faculty in 2017 report dedicating more time to administrative tasks than faculty in 2007 , but the difference is only 2 percentage points. 


\section{Table 3}

Independent Group T-test Results Comparing Participants' Responses to Four Variables in 2007 and 2017

\begin{tabular}{|c|c|c|c|c|c|c|}
\hline \multirow[t]{2}{*}{ Variables } & \multirow[t]{2}{*}{$t$} & \multirow[t]{2}{*}{$d f$} & \multirow[t]{2}{*}{$\begin{array}{l}\text { Sig. } \\
(2-\text { tailed })\end{array}$} & \multirow[t]{2}{*}{$\begin{array}{c}\text { Mean } \\
\text { difference }\end{array}$} & \multicolumn{2}{|c|}{$\begin{array}{l}95 \% \text { confidence } \\
\text { interval of the } \\
\text { difference }\end{array}$} \\
\hline & & & & & Lower & Upper \\
\hline DV1 Working hours per week & -3.64 & 2056 & .000 & -1.87 & -2.88 & -0.86 \\
\hline $\begin{array}{l}\text { DV3 Number of evaluation } \\
\text { occurrences }\end{array}$ & -4.32 & 2174 & .000 & -0.62 & -0.90 & -0.34 \\
\hline $\begin{array}{l}\text { DV4 \% of participation to } \\
\text { evaluation by professors }\end{array}$ & -4.07 & 2023 & .000 & -0.03 & 0.02 & 0.05 \\
\hline $\begin{array}{l}\text { DV5 Perception of administrative } \\
\text { cumbersomeness }\end{array}$ & -2.88 & 3806 & .004 & -0.12 & -0.19 & -0.04 \\
\hline
\end{tabular}

\section{By Whom Were Professors' Academic Activities Evaluated in 2007 and $2017 ?$}

The only variable with higher mean scores in 2007 than in 2017 was DV4-Proportion of participation to evaluation occurrences by professors. DV4 is a composite index created by adding the number of times participants checked that their teaching, research, and/or external activities were evaluated by one of the eight types of evaluators, and by dividing the number of times activities were evaluated by peers in the same or other departments from that total. Considering the complexity of this variable (three activities and eight types of evaluators) and taking into account that the evaluation of academic activity can be considered as a by-product of accountability, we disaggregated the 2007 and 2017 data to examine by whom professors reported being regularly evaluated.

Table 4 reveals that, in 2017, a larger proportion of professors reported that their research and teaching activities were more evaluated than in 2007 , and by all types of evaluators. The difference is particularly noticeable with teaching activities being more evaluated by students $(+11 \%)$, heads of departments $(+8 \%)$, senior administrators $(+9 \%)$, and other professors from the same department $(+8 \%)$. A larger proportion of professors also reported that their research was evaluated by senior administrative staff $(+11 \%)$, heads of departments $(+10 \%)$, and external reviewers (+6\%). On the contrary, compared to 2007 , a smaller proportion of faculty members in 2017 reported that their external (or service-oriented) activities were evaluated by peers, heads of departments, members of other departments, and students. Nevertheless, those activities were more evaluated by external reviewers $(+4 \%)$ and senior administrators $(+3 \%)$. 
Table 4

Evolution of Evaluation Occurrences by Type of Activity and Type of Evaluator Between 2007 and 2017

\begin{tabular}{|c|c|c|c|c|c|c|}
\hline & \multicolumn{2}{|c|}{$\begin{array}{l}\text { Teaching } \\
\text { activities }\end{array}$} & \multicolumn{2}{|c|}{$\begin{array}{l}\text { Research } \\
\text { activities }\end{array}$} & \multicolumn{2}{|c|}{$\begin{array}{l}\text { External } \\
\text { activities }\end{array}$} \\
\hline & 2007 & 2017 & 2007 & 2017 & 2007 & 2017 \\
\hline Your peers in your department & $35 \%$ & $43 \%$ & $39 \%$ & $41 \%$ & $39 \%$ & $31 \%$ \\
\hline $\begin{array}{l}\text { The head of your department or } \\
\text { unit }\end{array}$ & $56 \%$ & $64 \%$ & $48 \%$ & $58 \%$ & $55 \%$ & $47 \%$ \\
\hline $\begin{array}{l}\text { Members of other departments or } \\
\text { units at your institution }\end{array}$ & $13 \%$ & $14 \%$ & $18 \%$ & $19 \%$ & $14 \%$ & $11 \%$ \\
\hline Senior administrative staff & $25 \%$ & $34 \%$ & $27 \%$ & $38 \%$ & $26 \%$ & $29 \%$ \\
\hline Your students & $76 \%$ & $87 \%$ & $2 \%$ & $3 \%$ & $3 \%$ & $2 \%$ \\
\hline External reviewers & $7 \%$ & $9 \%$ & $47 \%$ & $53 \%$ & $7 \%$ & $11 \%$ \\
\hline
\end{tabular}

\section{In 2017, Were Some Faculty Members More Involved Than Others in Dealing With} Administrative Tasks?

Having noted a statistically significant increase in the faculty workload between 2007 and 2017, we were curious to examine on whom lied the burden of administrative tasks. Table 5 disaggregates data for the five DVs by professors' gender, age group, and academic rank.

Firstly, women reported working slightly fewer hours per week than their male colleagues but dedicating slightly more hours to administrative tasks. Female participants also indicated that their academic activities were evaluated more often and by other faculty members in a greater proportion. Concomitantly, the administrative process appeared more cumbersome for them than for male professors.

Secondly, the age groups who dedicated more time to administrative tasks were faculty members who are between 51 to 60 years old $(M=19 \%)$ and 61 to 70 years old $(M=19 \%)$. Faculty members under the age of 40 years old reported being evaluated the most often $(\mathrm{M}=$ 7.37) and by other professors in a larger proportion $(M=37 \%)$. The highest scores attributed to administrative cumbersomeness were given by faculty members between the ranges of 41 to 50 $(\mathrm{M}=3.99)$ and 51 to 60 years $(\mathrm{M}=3.99)$. 


\section{Table 5}

Comparing Participants of Evaluation (2017)

\begin{tabular}{lccccc}
\hline Academics & $\begin{array}{c}\text { Working } \\
\text { hours } \\
\text { per week }\end{array}$ & $\begin{array}{c}\text { \% time } \\
\text { dedicated to } \\
\text { administration }\end{array}$ & $\begin{array}{c}\text { Number of } \\
\text { evaluation } \\
\text { occurrences }\end{array}$ & $\begin{array}{c}\text { \% of } \\
\text { participation } \\
\text { to eval. by } \\
\text { professors }\end{array}$ & $\begin{array}{c}\text { Perception of } \\
\text { cumbersomeness }\end{array}$ \\
\hline Gender & & & & & \\
Male & 45.67 & $17 \%$ & 6.67 & $30 \%$ & 3.85 \\
Female & 44.96 & $18 \%$ & 7.06 & $33 \%$ & 3.99 \\
Age & & & & & \\
$<40$ & 43.38 & $13 \%$ & 7.37 & $37 \%$ & 3.86 \\
$41-50$ & 44.27 & $17 \%$ & 7.29 & $34 \%$ & 3.99 \\
$51-60$ & 46.45 & $19 \%$ & 6.89 & $30 \%$ & 3.84 \\
$61-70$ & 44.89 & $19 \%$ & 6.35 & $30 \%$ & 3.68 \\
$>70$ & 48.06 & $14 \%$ & 6.24 & $29 \%$ & \\
Academic rank & & & & & 3.89 \\
Assistant & 46.20 & $14 \%$ & 7.28 & $35 \%$ & 4.04 \\
Associate & 45.23 & $18 \%$ & 7.23 & $32 \%$ & 3.85 \\
Full & 45.79 & $19 \%$ & 6.66 & $30 \%$ & \\
\hline
\end{tabular}

Thirdly, considering that academic rank is significantly correlated to professors' age $\left(r_{\mathrm{s}}=0.50\right.$, $p<0.01$ ), our observations regarding age groups are applicable to ranks. Assistant professors declared working more hours $(M=46.20)$, dedicating less time to administrative tasks ( $\mathrm{M}=$ $14 \%)$, being evaluated more often $(M=7.28)$ and being evaluated by other faculty members in a larger proportion $(\mathrm{M}=35 \%)$. On the other hand, full professors reported dedicating a greater proportion of their time to administrative tasks $(M=19 \%)$, being less frequently evaluated ( $M=$ 6.66) and being less frequently evaluated by peers $(M=30 \%)$. Associate professors, for their part, perceived administrative processes as being more cumbersome $(M=4.04)$ than their colleagues. In sum, junior academics would be more frequently evaluated, mid-level academics would be more dissatisfied with the administrative cumbersomeness of their work, and senior academics would dedicate more time to administrative tasks.

\section{Discussion}

Using the Canadian data from the 2007 CAP study and 2017 APIKS study, this paper aimed to answer three research questions:

1. Are there significant differences in Canadian university professors' self-reported workload between 2007 and 2017 ?

2. By whom were professors' academic activities evaluated in 2007 and 2017 ? 
3. In 2017 , were some faculty members more involved than others in dealing with administrative tasks?

Findings suggest that academic workload increased significantly in 10 years, that academic activities are significantly more evaluated, although by academics themselves in a smaller proportion, and that the administrative burden lies more heavily on female and senior faculty members.

Those findings support the conclusions reached by other studies. The increase in faculty workload observed in Canadian research-intensive universities between 1996 and 2006 (Crespo \& Bertrand, 2013) seems to have continued between 2007 and 2017 and to be perceptible when all types of universities are considered. A future study could examine if the evolution in faculty workload varies by type of institution. One could wonder if a 2-hour-per-week increase corresponds to what Kouritzin (2020) named a "workload creep" (p. 1094), but participants did indicate working, on average, more than 45 hours per week, and even more if we only consider the 8 months during which classes are in session. Regarding the proportion of that workload coming from administrative tasks, there are few studies with which to compare our findings, but, in the United Kingdom, Tight (2010) had noted that the proportion of time dedicated to administrative tasks had also increased and represented $25 \%$ of professors' time. Our findings suggest that faculty members report dedicating, in $2017,18 \%$ of their time to administrative tasks, but although the increase since 2007 is significant, it is of very small magnitude (2\%).

Our analyses also mirror findings from other studies regarding how administrative tasks weigh more heavily on some academics than others, especially women (Craig et al., 2014; Link et al., 2017). As O'Meara et al. (2017) suggested, female faculty might feel a pressure to accept more administrative responsibilities than their male colleagues, despite a larger proportion of female academics in universities (Universities Canada, 2017). In terms of ranks, like Kyvik (2013) had noted in Europe, senior faculty members report working more hours than their junior colleagues who, like Porter and Umbach (2001) had suggested, could be expected to dedicate themselves to activities, mainly research, considered for their promotion. Assistant professors (who are, on average, more frequently 40 years old or younger) report working more hours per week and having their academic activities being more frequently evaluated and by other professors in a greater proportion. Professors who have not yet obtained tenure tend to dedicate more hours to preparing their courses and building up their research program because they have to get used to this job, but also because they must meet (or surpass) the implicit and explicit requirements of their colleagues, who are ultimately responsible for granting them with tenure (Acker \& Webber, 2016; Cook et al., 2020). Kim et al. (2016) have also shown that the implementation of tighter monitoring and evaluation systems in universities had a greater influence on assistant professors' activities, thus corroborating the tight coupling between evaluation and workload for assistant professors. Since our data do not indicate the types of 
evaluation activities that professors must face, this remains a hypothesis to be further tested. Academics of all ages somehow agree with the statement regarding the cumbersomeness of the administrative process, but retired professors and those close to retirement are less likely to agree than associate and women professors, groups often subjected to additional pressures and challenges (e.g., the glass ceiling, raising children, taking care of elderly dependents, raising funds for larger projects) related to career progress, gender equality, or relative competitiveness (Kyvik, 2013; O'Meara et al., 2017).

\section{Accountability, Evaluation, and the Technostructure}

The effective rise of faculty workload and administrative tasks between 2007 and 2017 occur in parallel with an accountability policy framing in higher education in several Canadian provinces (Fisher \& Rubenson, 2014). Accountability is a multifaceted concept, and, unlike Newton (2001) did in the United Kingdom, our study cannot confirm a direct causal relationship between accountability and the increase in faculty workload. Findings, however, shed light on professors' perception of evaluation processes, which are a concrete manifestation of accountability (O'Meara et al., 2017). Reported evaluation occurrences increased significantly in 10 years and professors' participation to those occurrences significantly decreased during the same period.

Beyond the burden of evaluations, our study indicates that, between 2007 and 2017, faculty evaluation (and the power it involves) has been transferred to other actors, following two distinct directions. Professors' participation in evaluating teaching activities has increased and remains an expression of collegiality as peer-based control rather than total immunity from peer scrutiny (Birnbaum, 1988; Hardy, 1996; Mintzberg, 1979). But our findings also suggest that evaluation has crept vertically, towards the upper level of the faculty staff (heads of units), and horizontally, towards other administrative or expert bodies, internal or external to universities. As administrative personnel (chairs and senior administrators) get more involved in evaluating teaching, accountability principles seep into assessment practices and may justify administrative oversight of academic work. Our results show an important increase in student evaluation of teaching (SET), which is in line with studies revealing how SET is used as a management tool by administrators (Cook et al., 2020; Hornstein, 2017). NPM tends to favour competition between universities (de Boer et al., 2005; Dill et al., 2004), and marketization is often accompanied by contractual obligations towards the State that incentives the continuous production of output measurements (Dill, 1998). As students are seen less as professional apprentices expected to conform to institutional culture, and increasingly as customers (Côté \& Allahar, 2007; Crespo et al., 2011; Winston, 1999), institutions benefit from increasing legitimacy to evaluate the students' satisfaction of the teaching they receive, legitimizing their opinions on the question (Hornstein, 2017). Our results show that the increase in SET is shadowed by an almost equivalent increase in administrators' (local or institutional) involvement in teaching assessment. 
Research activities are also increasingly evaluated, but while evaluation by peers remains constant, the participation of unit chairs and senior administrators is notable. This unequal evolution of responsibility over assessment processes tends to support the many observations regarding such a shift in Canada (Côté \& Allahar, 2007, 2011) and other countries (Whitchurch, 2012). First, this could relate to the intensification of research regulations through ethics protocols (Haggerty, 2004; Karram Stephenson, Jones, Fick, et al., 2020), and the role of central administrators and interstitial organizations in incentivizing and regulating profit-oriented research activities (Clark, 1998; Jessop, 2017).

Overall, the only types of evaluators who are more involved for all three types of academic activities' evaluation are senior administrative staff and external reviewers. This mirrors Geurts and Maassen's (2005) observation that professors perceived their activities were more evaluated by senior administrative staff. Two explanations could explain this evolution. Firstly, the accountability framework is often associated with a professionalized body of administrative staff (Kehm, 2015) proficient in the budget, finances and contracts, evaluating research projects, implementing teaching evaluation mechanisms, collecting institutional data, reporting on key performance areas or diversity and environmental standards, et cetera. (Hansen et al., 2019). Since this "support staff" work more with department chairs, deans, and vice-provosts than with professors (Kouritzin, 2020), academics fill out forms for them who, in the end, are responsible for making the institution accountable to public authorities. Secondly, as universities become more complex organizations and academic work implies a plurality of skills not generally developed by professors, universities employ professionals who are cognizant of research impact, learning technology, student development, equity standards, research ethics, international relations, trade and business law, bibliometric calculations, and team management. For Kyvik (2013), this administrative apparatus would relieve professors of some of the administrative work. However, considering their almost proprietary knowledge and their mastery of support infrastructure, professors must rely on their expertise and adjust their activities accordingly. This situation corresponds to Mintzberg's (1983) technostructure that relies on its expertise to develop systems of bureaucratic control. Multiple studies (e.g., Kallio et al., 2020; Normand, 2020) have shown how technostructures thrived in accountabilityfocused systems. The magnitude of differences between 2007 and 2017 remain, however, small and one could formulate a hypothesis according to which the high level of faculty unionization in Canada has served to protect academic traditions, such as collegiality (Gopaul et al., 2016).

\section{Conclusion}

The objective of this paper was to examine how faculty workload and academic activities' evaluation had evolved between 2007 and 2017, in a context marked by NPM and accountability in Canadian higher education. Relying on faculty perspectives collected in the 2007 CAP study and the 2017 APIKS study, our findings suggest that academic workload increased significantly 
in 10 years, that faculty members spend more time on administrative tasks, and that academic activities are significantly more evaluated, although less by academics themselves. These three findings are important as they corroborate the argument (see Craig et al., 2014; Geurts \& Maassen, 2005; Kouritzin, 2020; Shore, 2008; Tight, 2010) according to which accountability measures imposed on universities would have added to the administrative burden of professors who need to work more hours and dedicate more of their time to justify or demonstrate their academic activities' results and relevance.

Female academics also reported, in 2017, dedicating more time to administrative tasks, being more frequently evaluated, and perceiving the administrative process as more cumbersome than their male colleagues. Finally, the only types of evaluators who were more involved for all three types of academic activities' evaluation were senior administrative staff and external reviewers. Our interpretation of those findings is that the accountability policy framework in Canada is concomitant to universities' multiplying evaluation and reporting mechanisms, which could result in universities increasing the administrative and paperwork burden of faculty members (Allen, 2011), and hiring non-academic staff to help the institution in its diverse obligations (Hansen et al., 2019).

Our findings also suggest that the responsibility for evaluating academic activities has shifted vertically towards the heads of units, and horizontally towards administrative bodies of experts, either internal or external to universities. Future studies could examine how this power shift would influence collegial management practices within universities' decision-making bodies.

Since no formal definition of "administrative" tasks was provided in the surveys, a future study should examine what faculty members include in administrative tasks. For instance, is filling out ethics applications part of research or administration? Moreover, combining a policy analysis with empirical observations could help track how accountability policies at the provincial level influence universities' administrative procedures and, possibly, the administrative tasks performed by individual faculty members. In the end, one could wonder to what extent does the time involved in proving someone is working take time away from completing the work itself.

\section{Acknowledgements}

The APIKS survey of Canadian faculty was conducted by the research team of Glen A. Jones (University of Toronto), Grace Karram Stephenson (University of Toronto), Amy Scott Metcalfe (University of British Columbia), and Olivier Bégin-Caouette (Université de Montréal). This project was supported by the Ontario Human Capital Research and Innovation Fund and the Social Sciences and Humanities Research Council of Canada. This author was provided with access to data under the ethical protocols of this project and acknowledges the support of the research team in the development of the paper. 


\section{References}

Acker S., \& Webber M. (2016). Discipline and publish: The tenure review process in Ontario universities. In L. Shultz \& M. Viczko (Eds.), Assembling and governing the higher education institution. (pp. 233-255). Palgrave Macmillan. https://doi.org/10.1057/9781-137-52261-0_13

Allen, H. (2011). Faculty workload and productivity in Canada in an Era of global crises. In The NEA 2011 almanac of higher education (pp. 101-116). National Education Association. https://tinyurl.com/2pccc7ck

Anderson, J. E. (2006). Public policy-making (6th ed.). Wadsworth.

Birnbaum, R. (1988). How colleges work: The cybernetics of academic organization and leadership. Jossey-Bass.

Boring, A. (2017). Gender biases in student evaluations of teaching. Journal of Public Economics, 145, 27-41. https://doi.org/10.1016/j.jpubeco.2016.11.006

Broucker, B., \& De Wit, K. (2015). New public management in higher education. In J. Huisman, H. de Boer, D. D. Dill, \& M. Souto-Otero (Eds.), The Palgrave international handbook of higher education policy and governance (pp. 57-75). Palgrave Macmillan. https://doi.org/10.1007/978-1-137-45617-5_4

Buchanan, J., Gordon, S., \& Schuck, S. (2008). From mentoring to monitoring: The impact of changing work environments on academics in Australian universities. Journal of Further and Higher Education, 32(3), 241-250. https://doi.org/10.1080/03098770802220421

Canadian Association of University Teachers. (2019). CAUT almanac of post-secondary education: 3. Academic staff. https://www.caut.ca/resources/almanac/3-academic-staff

Clark, B. R. (1998). Creating entrepreneurial universities: Organizational pathways of transformation. Emerald.

Cook, C., Jones, J., \& Gibson-Sweet, M. (2020). The effects of control on academic engagement, work \&-life balance and work-life conflict: is how we manage and what we measure actually contributing to what we strive to pursue? In M. Antoniadou \& M. Crowder (Eds.) Modern day challenges in academia (pp. 168-182). Edward Elgar. https:/ / doi.org/10.4337/9781788119191

Côté, J. E., \& Allahar, A. L. (2007). Ivory tower blues: A university system in crisis. University of Toronto Press.

Côté, J. E., \& Allahar, A. L. (2011). Lowering higher education: The rise of corporate universities and the fall of liberal education. University of Toronto Press. 
Craig, R., Amernic, J., \& Tourish, D. (2014). Perverse audit culture and accountability of the modern public university. Financial Accountability \& Management, 30(1), 1-24. https://doi.org/10.1111/faam.12025

Crespo, M., Beaupré-Lavallée, A., \& Dubé, S. (2011). Regional delocalization of academic offer in Québec: A quasi-market manifestation in higher education. In P. Teixeira \& D. Dill (Eds.). Public vices, private virtues? Assessing the effects of marketization in higher education (pp. $211-231$ ). Brill. https://brill.com/view/book/edcoll/9789460914669/BP000012.xml

Crespo, M., \& Bertrand, D. (2013). Faculty workload in a research intensive university: A case study. Cirano. http://cirano.qc.ca/pdf/publication/2013RP-11.pdf

de Boer, H., Enders, J., \& Schimank, U. (2005). On the way towards new public management? The governance of university systems in England, the Netherlands, Austria, and Germany. In D. Jansen (Ed.), New forms of governance in research organizations-Disciplinary approaches, interfaces and integration (pp. 137-152). Springer. https://doi.org/10.1007/978-1-4020-5831-8_5

Dill, D. (1998). Evaluating the "evaluative State": Implications for research in higher education. European Journal of Education, 33(3), 361-377. https://www.jstor.org/stable/1503589

Dill, D., Teixeira, P., Jongbloed, B., \& Amaral A. (2004). Conclusion. In P. Teixeira B. Jongbloed, D. Dill, \& A. Amaral (Eds.) Markets in higher education: Rhetoric or reality? (HEDY, vol. 6, pp. 327-352). Springer. https://doi.org/10.1007/1-4020-2835-0_15

Eastman, J., Jones, G., Bégin-Caouette, O., Li, S., Noumi, C. \& Trottier, C. (2018). Provincial oversight and university autonomy in Canada: Findings of a comparative study of Canadian university governance. Canadian Journal of Higher Education / Revue canadienne d'enseignement supérieur, 48(3), 65-81. https://doi.org/10.7202/1057129ar

Enders J., de Boer H., \& Leišytė L. (2009). New public management and the academic profession: The rationalisation of academic work revisited. In J. Enders \& E. de Weert (Eds.), The changing face of academic life (pp. 36-57). Palgrave Macmillan. https://doi.org/10.1057/9780230242166_3

Finkelstein, M. J., \& Jones, G. A. (Eds.). (2019). Professorial pathways: academic careers in a global perspective. JHU Press. https://muse.jhu.edu/book/661 82

Fisher, D., \& Rubenson, K. (2014). Introduction and overview: PSE in three Canadian provinces. In D. Fisher, K. Rubenson, T. Shanahan, \& C. Trottier (Eds.), The development of postsecondary education systems in Canada: A comparison between British Columbia, Ontario, and Quebec, 1980-2010 (pp. 3-34). McGill-Queen's University Press.

Geurts, P., \& Maassen, P. (2005). Academics and institutional governance. In A. Welch (Ed.), The professoriate (pp. 35-58). Springer. https://doi.org/10.1007/1-4020-3383-4_3 
Gonzales, L. D. (2012). Responding to mission creep: Faculty members as cosmopolitan agents. Higher Education, 64(3), 337-353. https://doi.org/10.1007/s10734-011-9497-9

Gopaul, B., Jones, G. A., Weinrib, J., Metcalfe, A., Fisher, D., Gingras, Y., \& Rubenson, K. (2016). The academic profession in Canada: Perceptions of Canadian university faculty about research and teaching. Canadian Journal of Higher Education, 46(2), 55-77. https://doi.org/10.47678/cjhe.v46i2.185269

Guzmán-Valenzuela, C. (2018). Universities, knowledge and pedagogical configurations: Glimpsing the complex university. Educational Philosophy and Theory, 50(1), 5-17. https://doi.org/10.1080/00131857.2017.1313717

Haggerty, K. D. (2004). Ethics creep: Governing social science research in the name of ethics. Qualitative Sociology, 27(4), 391-414. https://doi.org/10.1023/B:QUAS.0000049239.15922.a3

Hall, A., \& Ferris, G. (2011). Accountability and extra-role behavior. Employee Responsibilities and Rights Journal, 23(2), 131 -144. https://doi.org/10.1007/s10672-010-9148-9

Hansen, H. F., Geschwind, L., Kivistö, J., Pekkola, E., Pinheiro, R., \& Pulkkinen, K. (2019). Balancing accountability and trust: University reforms in the Nordic countries. Higher Education, 78(3), 557-573. https://doi.org/10.1007/s10734-019-0358-2

Hardy, C. (1996). The politics of collegiality: Retrenchment strategies in Canadian universities. McGill- Queen's University Press

Hornstein, H. A. (2017). Student evaluations of teaching are an inadequate assessment tool for evaluating faculty performance. Cogent Education, 4(1), Article 1304016. https://doi.org/10.1080/2331186X.2017.1304016

Jessop, B. (2017). Varieties of academic capitalism and entrepreneurial universities. Higher Education, 73(6), 853-870. https://doi.org/10.1007/s10734-017-0120-6

Jones, G. A. (2011, November 12-14). The horizontal and vertical fragmentation of academic work: The academic profession in Canada and a proposal for a new international study. [Paper presentation]. International Workshop on the Changing Academic Profession, Wuhan, China. https://www.oise.utoronto.ca/hec/UserFiles/File/Research/Papers/The_Horizontal_and_V ertical_Fragmentation_of_Academic_Work.docx

Kallio, T. J., Kallio, K. M., \& Blomberg, A. (2020). From professional bureaucracy to competitive bureaucracy-Redefining universities' organization principles, performance measurement criteria, and reason for being. Qualitative Research in Accounting \& Management, $17(1)$, 82-108. https://doi.org/10.1108/QRAM-10-2019-0111 
Karram Stephenson, G., Jones, G. A., Bégin-Caouette, O., \& Metcalfe, A. S. (2020, March). Teaching, research and the Canadian professoriate: Findings from the 2018 Academic Profession in the Knowledge Society Survey. Higher Education Forum, 17 (pp. 25-41). Research Institute for Higher Education, Hiroshima University. http://doi.org/10.15027/48953

Karram Stephenson, G., Jones, G., Fick, E., Bégin-Caouette, O., Taiyeb, A., \& Metcalfe, A. (2020). What's the protocol? Canadian university research ethics boards and variations in implementing Tri-Council policy. Canadian Journal of Higher Education / Revue canadienne d'enseignement supérieur, 50(1), 68-81. https://doi.org/10.7202/1069652ar

Kehm, B. M. (2015). The influence of new higher education professionals on academic work. In U. Teichler \& W. Cummings (Eds.), Forming, recruiting and managing the academic profession (pp. 101-111). Springer. https://doi.org/10.1007/978-3-319-16080-1_6

Kim, H. B., Myung, S. J., Yu, H. G., Chang, J. Y., \& Shin, C. S. (2016). Influences of faculty evaluating system on educational performance of medical school faculty. Korean Journal of Medical Education, 28(3), 289-294. https://doi.org/10.3946/kjme.2016.34

Kouritzin, S. (2020). Extent and consequences of faculty members' workload creep in three Canadian faculties of education. Canadian Journal of Education, 42(4), 1092-1120. https://journals.sfu.ca/cje/index.php/cje-rce/article/view/4095

Kyvik, S. (2013). Academic workload and working time. Higher Education Quarterly, 67(1), $2-$ 14. https://doi.org/10.1111/hequ.12001

Link, A., Swann, C., \& Bozeman, B. (2007). A time allocation study of university faculty. Economics of Education Review, 27(4), 363-374. https://doi.org/10.1016/j.econedurev.2007.04.002

Marginson, S. (2009). Hayekian neo-liberalism and academic freedom. Contemporary Readings in Law and Social Justice, 1(1), 86-114. https://www.ceeol.com/search/articledetail?id=270216

Marini, G., \& Reale, E. (2016). How does collegiality survive managerially led universities? Evidence from a European survey. European Journal of Higher Education, 6(2), 111-127, https:/ / doi.org/10.1080/21568235.2015.1070676

Mintzberg, H. (1979). The structuring of organizations: A synthesis of the research. Prentice Hall. Mintzberg, H. (1983). Power in and around organizations. Prentice Hall.

Mitchell, K., \& Martin, J. (2021). Gender bias in student evaluations-Corrigendum. PS: Political Science \& Politics, 54(1), 192. https://doi.org/10.1017/S1049096520000566

Neave, G. (1998). The evaluative state reconsidered. European Journal of Education, 33(3), 265284. https://www.jstor.org/stable/1503583 
Newton, J. (2001). Views from below: Academics coping with quality. Quality in Higher Education, 8(1), 39-61. https://doi.org/10.1080/13538320220127434

Normand, R. (2020). France: The French state and its typical "agencies" in education. Policy transfer and ownership in the implementation of reforms. In H. Ärlestig \& O. Johansson (Eds.), Educational authorities and the schools (pp. 151-168). Springer. https://doi.org/10.1007/978-3-030-38759-4_9

O’Meara, K., Kuvaeva, A., Nyunt, G., Waugaman, C., \& Jackson, R. (2017). Asked more often: Gender differences in faculty workload in research universities and the work interactions that shape them. American Educational Research Journal, 54(6), 1154-1186. https://doi.org/10.3102/0002831217716767

Porter, S., \& Umbach, P. (2001) Analyzing faculty workload data using multilevel modeling. Research in Higher Education, 42(2), 171-196. https://doi.org/10.1023/A:1026573503271

Shore, C. (2008). Audit culture and illiberal governance: Universities and the politics of accountability. Anthropological Theory, 8(3), 278-298. https:/ / doi.org/ $10.1177 \% 2 F 1463499608093815$

Statistics Canada. (2019). Number of full-time teaching staff at Canadian universities, by rank, sex: Table 37-10-0076-01. https://doi.org/10.25318/3710007601-eng

Tight, M. (2010). Are academic workloads increasing? The post-war survey evidence in the UK. Higher Education Quarterly, 64(2), 200-215. https://doi.org/10.1111/j.14682273.2009.00433.x

Trow, M. (1973). Problems in the transition from elite to mass higher education. Carnegie Commission on Higher Education. https://files.eric.ed.gov/fulltext/ED091983.pdf

Trow, M. (1994). Managerialism and the academic profession: The case of England. Higher Education Policy, 72), 11-18. https://doi.org/10.1057/hep.1994.13

Universities Canada. (2017, November 28). Percentage of female faculty at Canadian universities is growing - Statistics Canada. https://www.univcan.ca/media-room/mediareleases/percentage-female-faculty-canadian-universities-growing-statistics-canada/

Whitchurch, C. (2012). Reconstructing identities in higher education: The rise of "third space" professionals. Routledge. https://doi.org/10.4324/9780203098301

Winston, G. (1999). Subsidies, hierarchy and peers: The awkward economics of higher education. Journal of Economic Perspectives, 13(1), 13-36. https:// www.aeaweb.org/articles?id=10.1257/jep.13.1.13

Zhao, J., \& Gallant, D. J. (2012). Student evaluation of instruction in higher education: Exploring issues of validity and reliability. Assessment \& Evaluation in Higher Education, 37(2), 227235. https://doi.org/10.1080/02602938.2010.523819 